\title{
Development of a simulation system in mandibular orthognathic surgery based on integrated three-dimensional data
}

\author{
Yoshihide Mori • Hidetaka Shimizu • \\ Katsuhiro Minami • Tae-Geon Kwon • Takamitsu Mano
}

Received: 11 October 2009 /Accepted: 11 October 2010/Published online: 28 October 2010

(C) The Author(s) 2010. This article is published with open access at Springerlink.com

\begin{abstract}
Purpose Surgical simulation should reflect the 3D movement of dentition and the resultant movement of the osteotomized segments, which can influence surgical outcome. The present study was aimed at developing a new simulation system that enables virtual osteotomy of a given surgical situation and
\end{abstract}

\section{Y. Mori $(\bowtie)$}

Department of Oral and Maxillofacial Surgery,

Graduate School of Dentistry, Kyushu University,

3-1-1 Maidashi, Higashi-ku,

Fukuoka, Fukuoka 812-8582, Japan

e-mail: y-mori@dent.kyushu-u.ac.jp

\section{Y. Mori}

Center for Advanced Medical Engineering and Informatics,

Osaka University,

2-2 Yamadaoka,

Suita, Osaka 565-0871, Japan

\section{H. Shimizu}

Department of Oral and Maxillofacial Surgery II,

Graduate School of Dentistry, Osaka University,

1-8 Yamadaoka,

Suita, Osaka 565-0871, Japan

\section{K. Minami}

Cleft Lip and Palate Center, Aichigakuin University Hospital,

2-1-1 Suemori-dori, Chikusa-ku,

Nagoya, Aichi 464-8651, Japan

\section{T.-G. Kwon}

Department of Oral and Maxillofacial Surgery,

College of Dentistry, Kyungpook National University,

101 Dongin-dong, Chung-gu,

Daegu 700-422, South Korea

\section{T. Mano}

Department of Oral and Maxillofacial Surgery,

Graduate School of Medicine, Yamaguchi University,

1-1-1 Minamikogushi,

Ube, Yamaguchi 755-8505, Japan evaluation of the bony interference between the osteotomized segments of the mandible.

Subjects and methods The data of 3D computer tomography (CT) for maxillomandibular dental casts were integrated into the standard coordinates of a 3D cephalogram. To evaluate the accuracy of the system, measurement errors of the 3D CT virtual model from a dry skull were compared with the computer simulation system and a contact-type 3D digitizer. To examine the clinical accessibility, 15 mandibular prognathism patients with mild to severe asymmetry were evaluated with the simulation program.

Results The average error of measurement in all directions was $1.31 \mathrm{~mm}$. It was possible to simulate various osteotomy procedures by conversion of the $3 \mathrm{D}$ coordinates of the dental cast and CT data into the standard coordinate system of a 3D cephalogram. Using this simulation system, it was possible to prevent condylar torque or segment malpositioning by removing the bony interference visualized by a $3 \mathrm{D}$ virtual model.

Conclusion A new system, which enables the precise visualization of osteotomized segments and calculation of bony interference, was proposed in the present study. This new system provides an acceptable precision of treatment planning of orthognathic surgery, especially for facial asymmetry.

Keywords Surgical simulation - Three-dimensional · Computer tomography (CT) · Orthognathic surgery · Sagittal split ramus osteotomy (SSRO)

\section{Purpose}

As orthognathic surgeries are usually carried out intraorally, it is difficult to understand the surgical situation thoroughly 
during the operation. In mandibular orthognathic surgery in particular, the location and degree of interference of bony segments cannot be readily assessed in the operating room, even though they can influence the surgical outcome. In regular clinical cases, prediction on this issue was usually carried out two-dimensionally, and there have been fundamental limitations to understanding the 3D structure and 3D movement of proximal and distal segments. Recent advancement in computer-aided surgical simulation has now enabled interactive visualization, simulation, and surgical prediction [1-4]. To predict the postsurgical skeletal profile and dentition three-dimensionally, we should combine the information from 3D computer tomography (CT), dental models, and cephalometric radiographs. Former surgical simulation with 3D CT $[2,5,6]$ could be applied only as a reference for real surgery because the prediction of postoperative profile in orthognathic surgery was not based on the movement of the osteotomized bony segments, including dentition. The problems in orthognathic surgical simulation including dentition were attributed to blurring from metallic restorations in the 3D CT image. Fuhrmann et al. [7] developed a prediction system with transfer of replaceable maxillary and mandibular dental casts to the $3 \mathrm{D}$ CT skull model. Even though this was the first attempt to predict a bony gap and interference in asymmetric facial deformities with an integrated 3D model and dental cast, there were problems such as high cost and time, and most importantly, the accuracy of the system had not been fully documented. Moreover, the accuracy of the 3D CT model was not always sufficient to use in standard surgical procedures $[8,9]$.

To evaluate the $3 \mathrm{D}$ change of the skeletal landmarks, X-ray stereometric method or 3D cephalometry was also developed $[10,11]$ and used in orthognathic surgery [12]. An accurate method for the integration of the 3D coordinates of a 3D cephalogram and dental cast was proposed [13]. Recently, various attempts have been made to integrate the coordinates of a 3D CT, 3D cephalogram, and dental casts in the same reference coordinates without the problem of image distortion of the CT by orthodontic brackets or arch wires. However, the accuracy of these systems has been unclear or the ability to perform virtual reality has not been introduced $[3,14]$.

The purpose of the research presented here was to develop a new surgical simulation system, which can permit precise calculation and visualization of the bony interference after surgery of the mandible. To evaluate the validity of this system, landmarks on a dry skull were compared with those of a computer simulation system and contact-type 3D digitizer. This system was also applied to patients, and the surgical results were evaluated.

\section{Subjects and methods}

Development of a simulation system for orthognathic surgery

\section{Data acquisition, processing, and system configuration}

3D data integration was carried out as follows: First, the 3D coordinates of a 3D cephalogram were obtained from a set of lateral and frontal cephalograms [13]. Second, the 3D data of the maxillomandibular dental casts were converted to the coordinate system of a $3 \mathrm{D}$ cephalogram $[14,15]$. 3D measurements of the dental casts were carried out manually with a contact-type 3D digitizer (Tristation 400CNC; Nikon, Japan). The measured dental landmarks were U1 (upper incisor tip), UR7 (right upper second molar cusp tip), UL7 (left upper second molar cusp tip), L1 (lower incisor tip), LR7 (right lower second molar cusp tip), and LL7 (left lower second molar cusp tip). The relationship between the pre- and predicted postsurgical occlusions was calculated by a model of the surgery [16].

Third, the CT data and 3D cephalogram data were integrated [16]. The CTs were taken with a continuous $2 \mathrm{~mm}$ slice thickness, $3 \mathrm{~mm}$ slice interval, $320 \times 320$ matrix, and parallel to the occlusal plane by a CT9200 (Yokogawa Medical, Japan). The data were transferred to a personal computer (OS, Windows XP; Microsoft, USA). The skull image reconstructions from the CT slices were achieved using the "Marching cubes" method [17], which enables control of the bony images by manipulation of polygon meshes. Before making the 3D image, specific slices were chosen and metallic artifacts were removed. Then, the 3D image was rotated and translated to fit the same skeletal landmarks of the mandibular inferior border of a $3 \mathrm{D}$ cephalogram so that $\mathrm{CT}$ data could be converted to standard 3D cephalometric reference coordinates (Fig. 1).

The standard coordinate system was designed in our previous study [13]. The plane determined by the midpoint of the bilateral porion ( $\mathrm{PoC}$ ) and bilateral orbita was defined as the standard plane. The $\mathrm{PoC}$ was fixed as the origin, and the line from the $\mathrm{PoC}$ to midpoint of the bilateral orbita (OrC) was defined as the $x$-axis. The straight line passing through right and left porions was defined as the $z$-axis, and the straight line vertical to the $x z$-plain was defined as the $y$-axis. Dental landmarks (L1, LR7, LL7) were displayed as a triangle.

The system was developed with the AVS/Express developer Ver. 6.2 (Advanced Visual Systems, USA). This software enables the processing of complicated medical images and can be modified or supplemented by the operator. 
Fig. $13 \mathrm{D}$ integration of the CT, cephalogram, and dental casts. a 3D CT data on the standard coordinates of a 3D cephalogram (artifacts had not yet been removed). The Frankfurt plane determined by the midpoint of the bilateral porion (PoC) and bilateral orbita was defined as the standard plane. b The mandibular occlusal plane consisting of three dental landmarks (L1, LR7, LL7) was registered on the 3D CT
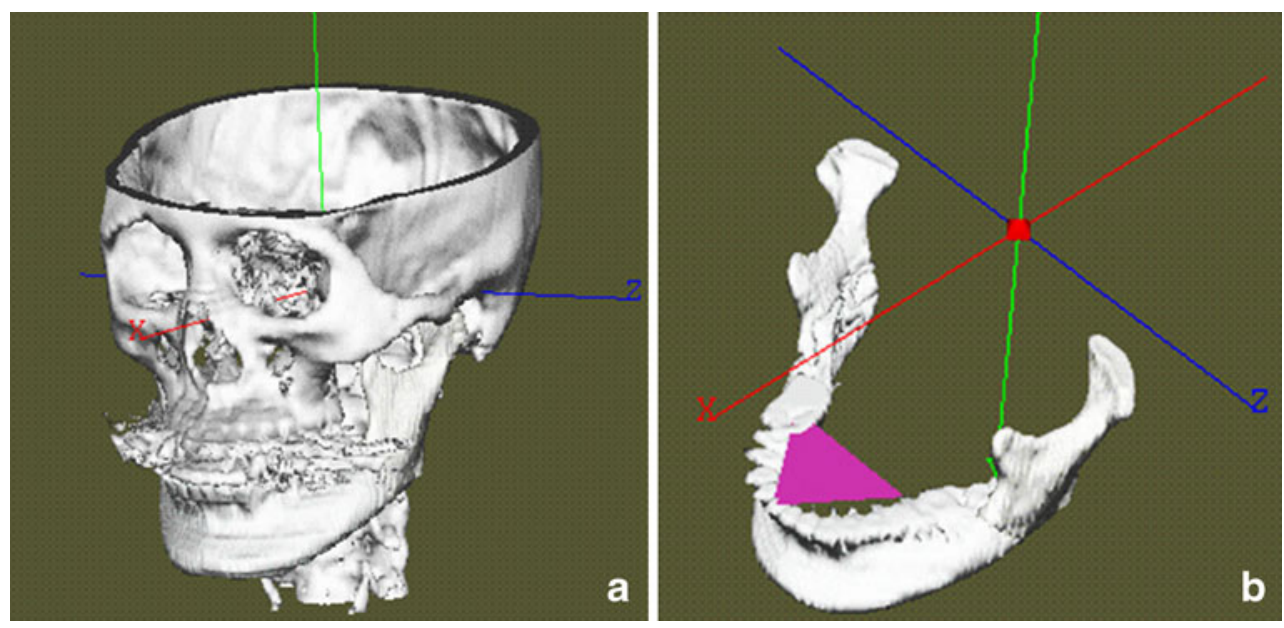

\section{Simulation of virtual osteotomy}

Sagittal split of the mandibular ramus Simulation of splitting of mandibular ramus was a difficult procedure, and no previous reports had demonstrated it. As the splitting is performed between the cortical and cancellous bone layers of the ramus, it is possible to discriminate the cortical layer from the cancellous bone layer virtually by adjusting the threshold value according to different CT numbers or Hounsfield scales [18] of the cortical and cancellous layers. First, the osteotomy line was set the same as for an ordinary sagittal split ramus osteotomy (SSRO) [19]. Then, the splitting of the corticocancellous bone was delineated in each of the 2D CT slices. This step was carried out automatically when we used a tool (function of area abstract) in the software.

Mobilization of the osteotomized distal segment In mandibular orthognathic surgery, the distal segment of the mandible moves according to the predicted occlusion. It is possible to obtain 3D data of the preoperative and predicted positions of mandibular dental landmarks (LL1, LR7, LL7) with the 3D digitizer. According to positional differences of these landmarks, transition matrices for the preoperative and predicted positions of the distal segment of the mandible in the standard reference coordinates can be made.

Evaluation of the bony interference When an asymmetric advancement or setback is performed, the proximal segment can rotate owing to bony contact with the distal segment. The amount of bony interference can be assessed by calculation of the overlapping area of the proximal and distal segments. The volume of bony interference is referred to as the "degree of interference" and color-coded.
Accuracy of the $3 D$ CT image

Reliability of the data measured in the 3D virtual model was investigated by comparing it against the contact-type 3D digitizer (Tristation 400CNC; Nikon, Japan). As the 3D digitizer has a spatial error accuracy of $\pm 5 \mu \mathrm{m}$, the values obtained with this apparatus are considered as the true values. Both the $3 \mathrm{D}$ CT image simulation system and the 3D digitizer measured a dry skull, which was marked with 11 landmarks, ten times. The $x$-, $y$-, and $z$-coordinates obtained by each system were trans-coordinated to the standard reference coordinates as mentioned, and each landmark was compared.

The standard error was calculated as a lineal sum of the mean of the difference and standard deviation divided by the square root of the sample size $(n=10) . \mathrm{SE}=u / \sqrt{n}+\delta$, where $u$ is square root of the unbiased variance, $n$ is number of measurements, and $\delta$ is difference of the means of the observations made with the $3 \mathrm{D}$ digitizer and virtual $3 \mathrm{D} \mathrm{CT}$ model.

\section{Clinical application}

Fifteen patients (five males and ten females, mean age of 24 years) who underwent a bilateral SSRO (BSSRO) were selected to evaluate the clinical usefulness of the simulation system. Three sets of data-CT, 3D cephalogram, and dental casts-were taken before and 6 months after the operation for all patients. Even though the positions of the mandibular proximal segments were secured with a mandibular repositioning system [20], this cannot ensure complete rigidity mediolaterally. For this reason, it is difficult to detect the exact site and degree of bony interference in the operation field with only the naked eye. The amount and area of bony interference could be indicated in the simulation program for each patient 
preoperatively. During the operation, the predicted areas of interference were trimmed and removed according to the information from the surgical simulation program. After confirming the complete passive adaptation between the proximal and distal segments, all the mandibles were fixed with screws except for in one case of unilateral wire fixation. To evaluate the postsurgical changes of the proximal segments, the intercondylar distance $(\mathrm{Co}(\mathrm{R})-\mathrm{Co}$ $(\mathrm{L}))$ and intercoronoid distance $(\mathrm{Cr}(\mathrm{R})-\mathrm{Cr}(\mathrm{L}))$ were measured in a postoperative $3 \mathrm{D}$ CT image.

\section{Results}

\section{Construction of the system}

It was possible to simulate various osteotomy procedures by conversion of the $3 \mathrm{D}$ coordinates of the dental cast and CT data to the standard coordinate system of a 3D cephalogram (Figs. 2 and 3). Additionally, it was possible to calculate and visualize the site and amount of bony interference between the proximal and distal segments of the mandible (Fig. 4). The program was neither overly difficult nor time-consuming for the operator.

Measurement standard errors of the 3D CT virtual model from the dry skull are listed, and the standard error of the $x$-, $y$-, and $z$-coordinates were $1.08,2.12$, and $0.73 \mathrm{~mm}$, respectively, while the average error in all directions was $1.31 \mathrm{~mm}$ (Table 1).
Clinical application

The amount of interference varied in terms of size, shape, and thickness of the mandibular ramus, as well as the amount of setback and degree of rotational movement of the mandible. With the information on the bony interference, it was possible to reposition the mandibles passively without conspicuous deviation of the condylar segments during the operation. It was difficult to correlate the asymmetry, prognathism, and volume of the proximal segment and degree of interference; however, in the cases of severe mandibular asymmetry (cases 6,12 , and 13), the amounts of predicted interference between the bone segments were at least three times larger than those of the mandibular prognathism within $5 \mathrm{~mm}$ of the chin deviation (Table 2). In cases of severe mandibular prognathism, even a small amount of asymmetric mandibular setback resulted in significant bony interference (cases 7 and 10).

\section{Discussion}

SSRO is one of the most popular surgeries used for dentofacial deformities, including mandibular prognathism, retrognathism, and/or asymmetry, because of its reliability and wide range of indications. The condylar position in the glenoid fossa can be changed [21, 22] with screw fixation in BSSRO for asymmetrical mandibular advancement or setback. The condylar displacement during the surgery can
Fig. 2 Simulation of BSSRO for a case of mandibular deviation. The upper row is the presurgical view (left, anterior; right, axial). The lower row is the simulation image (left, anterior; right, axial)
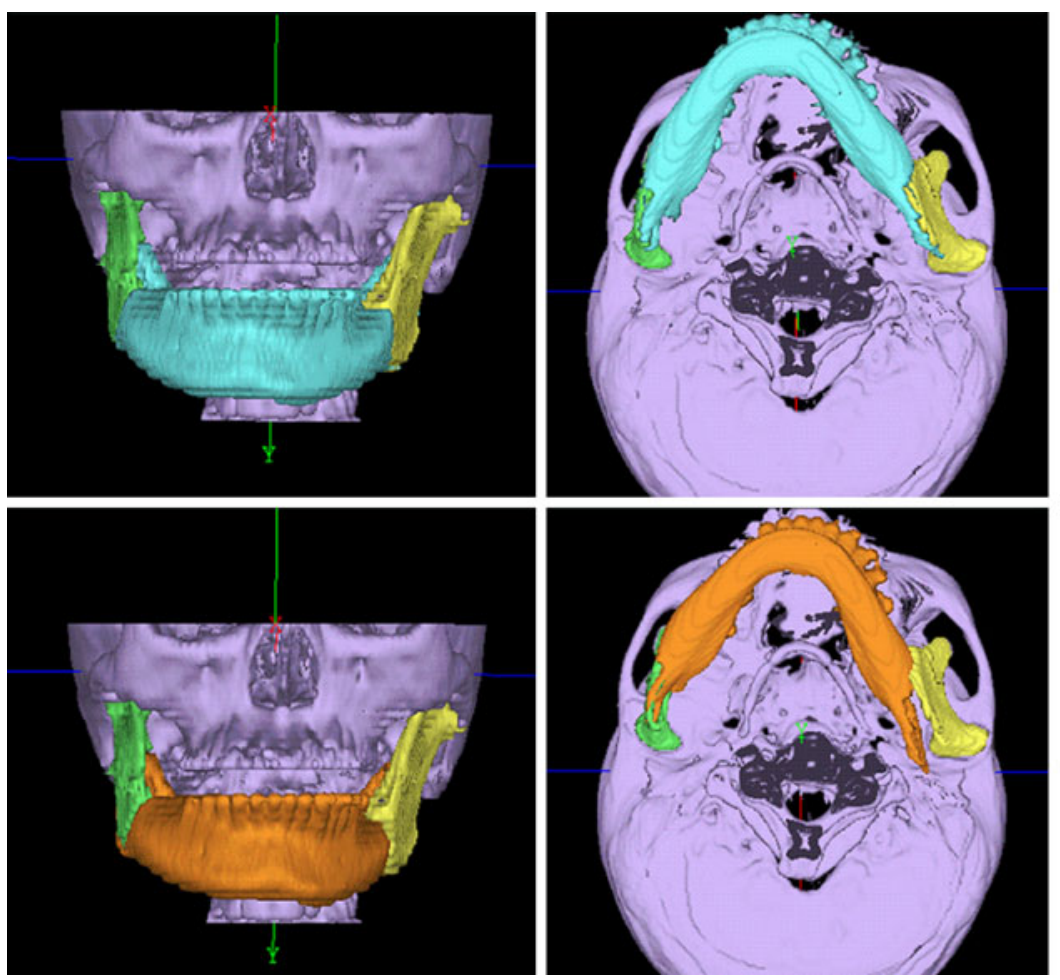

Pre operation

Simulation 

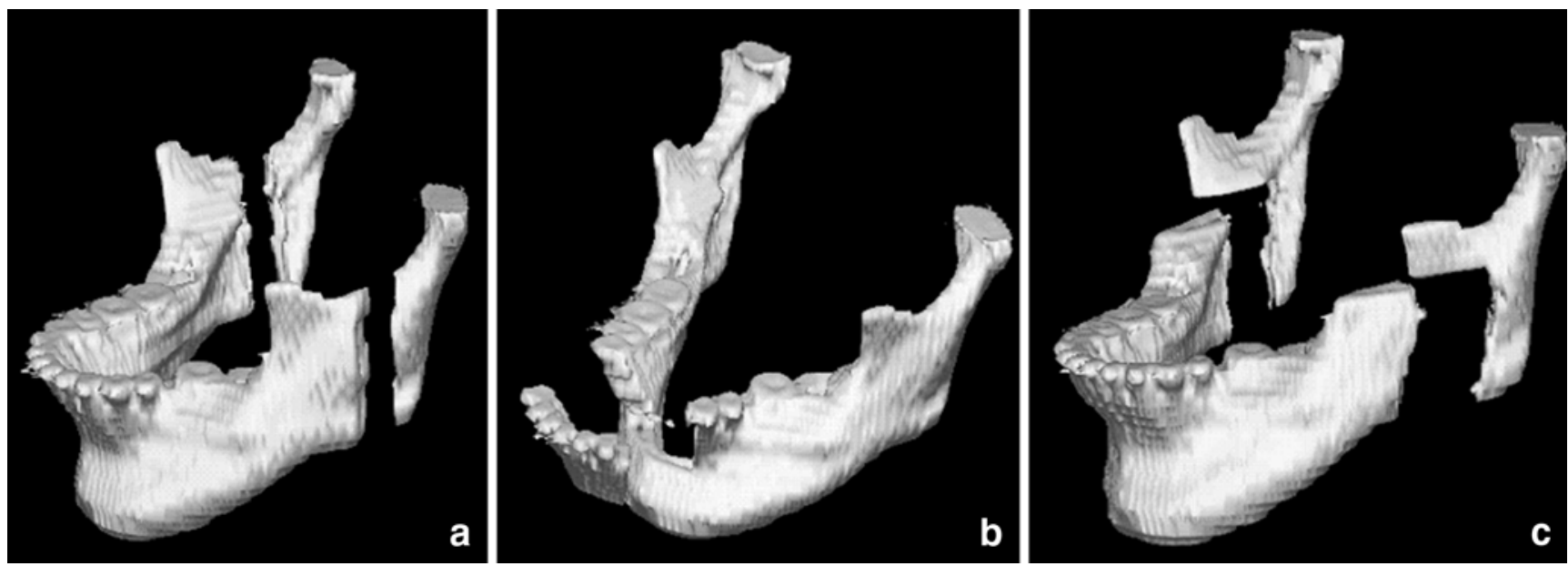

Fig. 3 Simulation of various mandibular surgeries. a Vertical ramus osteotomy. b Anterior alveolar osteotomy of the mandible. c Inverted L osteotomy of the mandible

influence the long-term stability and temporomandibular joint function and sometimes result in inferior alveolar nerve compression. However, treatment planning of the surgery has relied on lateral cephalometry without any information on transverse change of the mandibular position. To predict the 3D relation between the proximal and distal segments, the ramus fragment was attached to a conventional articulator [23] or the dental model was aligned to an acrylic model of the dry mandible (not one's own mandible) [24]. These methods could demonstrate possible interference between the segments, but could not show the bony interference or gap accurately because of a lack of a scientific system to ensure quantitative analysis.

Recent real-life-sized 3D solid models from CT scans can be applied to treatment planning for this purpose. Although CT scans had been thought to give more risk of radiation exposure almost all surgeons now refer to CTs, which give useful information before orthognathic surgery. Fuhrmann et al. [7] and Onish and Maruyama [25] reported the integration of dental casts into 3D solid models using a face bow transfer, a method which has been proven to be inaccurate in some cases because of the flexibility of skin references for face bow transfer [26]. Additionally, manipulation of the $3 \mathrm{D}$ solid model is destructive, and there is a difference between the actual skull and a 3D solid model, which implies that it is better to use a $3 \mathrm{D}$ virtual image if we want to perform surgical simulations with various functions, including calculation and accurate mobilization, without any degradation of the database.

3D imaging produced by building up 2D transverse slices was first reported by Herman and Liu [27]. Since the 1980s, 3D CTs have been used as a useful diagnostic tool for the treatment planning of maxillofacial deformities $[5,28]$ and are now widely used in regular clinical cases $[29,30]$ for
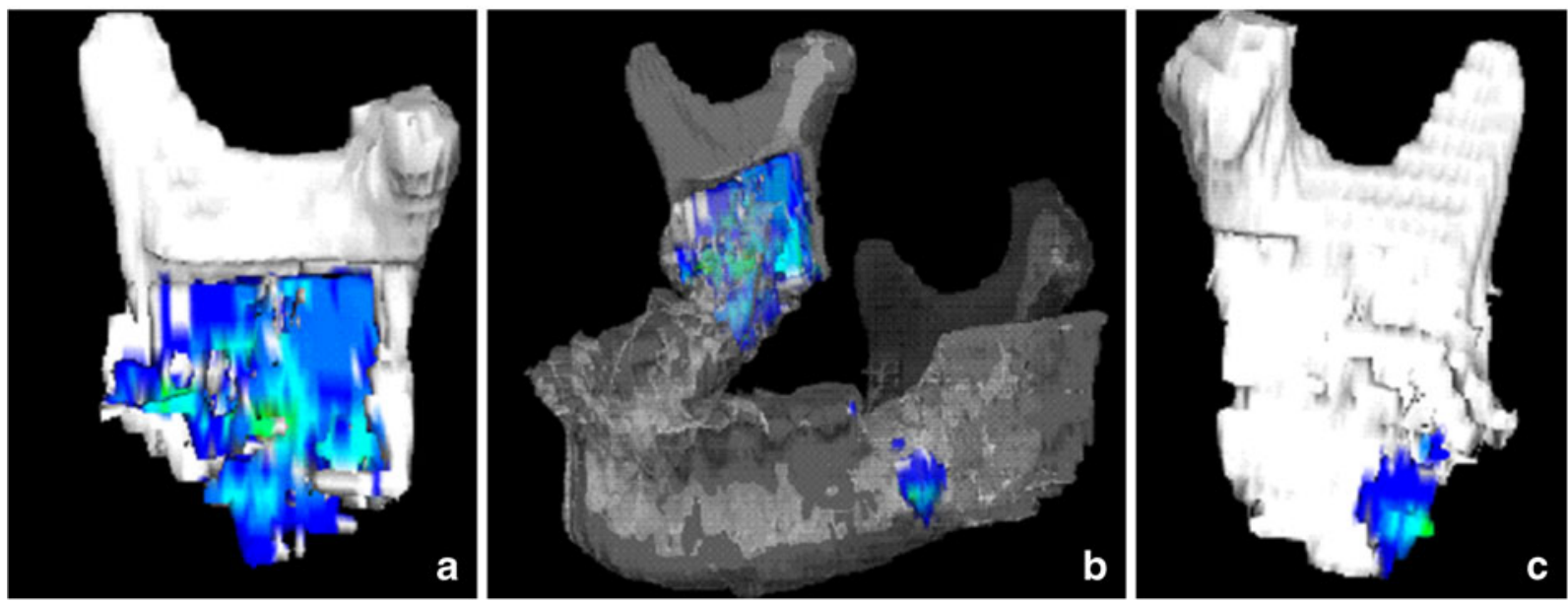

(mm)

Fig. 4 Detection of segmental interference (the case of Fig. 2). a Interference of the deviational side on the medial segment. b Overview of the interference on the mandible. $\mathbf{c}$ Interference of the non-deviational side on the medial segment. The color bar shows the degree of interference 
Table 1 Measurement errors of the 3D CT virtual model from the dry skull

\begin{tabular}{llll}
\hline Landmarks on the dry skull & \multicolumn{3}{l}{ Standard error (mm) } \\
\cline { 2 - 4 } & $x$ & $y$ & $z$ \\
\hline Nasion & 2.70 & 3.26 & 0.01 \\
Orbitale (right) & 1.68 & 0.43 & 0.20 \\
Orbitale (left) & 0.19 & 0.77 & 2.03 \\
Porion (right) & 0.06 & 0.57 & 0.17 \\
Porion (left) & 0.09 & 1.09 & 0.45 \\
B point & 0.89 & 3.09 & 0.54 \\
Gonion (right) & 1.98 & 4.05 & 0.68 \\
Gonion (left) & 0.50 & 3.27 & 1.10 \\
Mental foramen (right) & 1.16 & 2.17 & 1.66 \\
Mental foramen (left) & 1.60 & 1.60 & 0.85 \\
Pogonion & 1.01 & 3.02 & 0.32 \\
Mean & 1.08 & 2.12 & 0.73 \\
Mean (in all directions) & & 1.31 & \\
\hline
\end{tabular}

surgical planning and evaluation. However, 3D image reconstruction only for viewing uses remains largely subjective and cannot provide any virtual operative environment.

The accuracy of the 3D virtual image depends on various factors, such as the data of CT scans, 3D rendering software, and image artifacts. Recent developments in hardware and software of CT technology provide extended accuracy in 3D CTs. Now, CT scanning equipment has been improved in terms of the accuracy in the vertical direction. If the operator controls the values of voxel density to be rendered, it is possible to show the inner hard and soft tissue structures in a selected cutoff plane. However, the metallic artifacts of restoration or brackets on the teeth can interfere with accurate reproduction of the 3D image, including dentition. For these reasons, accurate simulation could not be widely used in orthognathic surgeries including for dentition. Thus, translocation of the osteotomized segments into a desirable occlusal relationship has not been possible. The greatest problem has been to synchronize the dental model and 3D skull image at the same reference coordinates.

Application of a 3D CT for orthognathic surgical planning, especially the function of 3D virtual osteotomy, has previously been presented. Girod et al. [6] introduced a simulation system in which the shifting of bony segments could be computed. However, the simulation of osteotomy in mandibular surgery was carried out with "cutting planes", which is not the same as an osteotomy procedure in an operating room. Recently, Xia et al. [31] reported a system that could move the osteotomized bone segments freely with quantitative movement data based on 2D cephalometry or clinical experience. However, intercuspation of teeth and the amount of bone displacement should be evaluated simultaneously. Postsurgical mandibular position is determined by the maximal intercuspation of the maxillomandibular dentition and not by the predicted position of paper surgery or clinical inspection.

Table 2 Predicted interference between the bone segments and postsurgical change of the position of the condyle and coronoid points

\begin{tabular}{|c|c|c|c|c|c|c|c|}
\hline \multirow[t]{2}{*}{ Case no. } & \multicolumn{2}{|c|}{$\begin{array}{l}\text { Predicted movement of } \\
\text { he proximal segment }(\mathrm{mm})\end{array}$} & \multicolumn{3}{|c|}{$\begin{array}{l}\text { Predicted volume of the interference between } \\
\text { the proximal and distal segments }\left(\mathrm{mm}^{3}\right)\end{array}$} & \multicolumn{2}{|c|}{$\begin{array}{l}\text { Postsurgical change of the proximal segment } \\
\text { (intercondylar and intercoronoid distance; } \mathrm{mm} \text { ) }\end{array}$} \\
\hline & Right & Left & Right & Left & Sum & $\mathrm{Co}(\mathrm{R})-\mathrm{Co}(\mathrm{L})$ & $\mathrm{Cr}(\mathrm{R})-\mathrm{Cr}(\mathrm{L})$ \\
\hline 1 & 8 & 7 & 0 & 36 & 36 & -0.77 & -1.06 \\
\hline 2 & 5 & 6.5 & 0 & 282 & 282 & 1.91 & -0.43 \\
\hline 3 & 8 & 7 & 11 & 0 & 11 & -0.02 & 2.07 \\
\hline 4 & 6 & 6 & 120 & 65 & 285 & 0.77 & -1.68 \\
\hline 5 & 6 & 8 & 11 & 28 & 39 & -0.21 & 0.99 \\
\hline 6 & 4 & 4 & 0 & 996 & 996 & -0.50 & -1.45 \\
\hline 7 & 8 & 7 & 0 & 272 & 272 & -0.43 & 2.16 \\
\hline 8 & 4 & 9 & 128 & 0 & 128 & 0.78 & -0.20 \\
\hline 9 & 8 & 7 & 188 & 0 & 188 & 0.23 & 0.11 \\
\hline 10 & 9 & 12.5 & 0 & 243 & 243 & 2.03 & 2.70 \\
\hline 11 & 10 & 6 & 0 & 0 & 0 & 0.73 & -0.76 \\
\hline 12 & 8 & -2.5 & 1,411 & 0 & 1,411 & -2.47 & 4.70 \\
\hline 13 & 0 & 2 & 0 & 894 & 894 & 0.71 & -0.60 \\
\hline 14 & 6 & 6 & 142 & 0 & 142 & -0.54 & -0.54 \\
\hline 15 & 7 & 8 & 0 & 40 & 40 & -1.18 & 3.14 \\
\hline \multicolumn{5}{|c|}{ Mean (SD) } & $331.13(423.22)$ & $0.89(0.69)$ & $1.51(1.23)$ \\
\hline
\end{tabular}

Bilateral sagittal split ramus osteotomy was performed in consideration of the amount of bony interference between each segment 
It is technically difficult to superimpose dental study casts directly onto a 3D CT because there are no discernable reference points common between the two. However, 3D cephalograms taken from frontal and lateral cephalograms have skeletal landmarks corresponding to those in 3D CT, and a 3D cephalogram has dental landmarks corresponding to those in a dental cast. Thus, it is possible to integrate the data of a dental cast and $3 \mathrm{D} \mathrm{CT}$ if we use a 3D CT as a transition component of the system.

In the present study, the three landmarks of a dental cast were digitized with an accurate $3 \mathrm{D}$ digitizer and superimposed to the same landmarks identifiable in a cephalogram. The 3D coordinates of the landmarks on the dental cast were best-fitted to a 3D cephalogram mathematically with transition matrices [14]. Then, the 3D CT coordinates were transformed to $3 \mathrm{D}$ cephalometric coordinate reference (standard coordinates of the system) automatically when the operator identified the cephalometric landmarks on the 3D virtual model. Bettega et al. [3] developed a simulation system based on the integration of 3D cephalometry and dental models using a 3D optical localizer. Although the degree of accuracy and the function of various osteotomies were not well documented in this paper, the idea of utilizing a 3D cephalogram was similar to ours. To our knowledge, this is the first attempt to analyze bony interference quantitatively and perform osteotomy in a manner very similar to real surgery. To reflect our experience, surgeons could obtain enough knowledge of gap or interference between the segments and thus could prevent excessive torque or sagging of the condyle in the glenoid fossa. Comparing clinical situations and surgical simulations, the sites of bony interference nearly coincided with what the simulation system had predicted. It will be helpful for not only inexperienced doctors but also experienced surgeons. Actually, in one case of severe mandibular asymmetry (case 12), bony interference remained, but for thorough bone trimming during the operation, which resulted in deviation of the proximal segment. The simulation revealed that the degree of interference can be reduced with a selective change in surgical plan from SSRO to intraoral vertical ramus osteotomy or another surgical procedure on the ipsilateral side.

The accuracy of the present system revealed an average error of $1.31 \mathrm{~mm}$, which is within 2 pixels $(1$ pixel $=0.8 \mathrm{~mm})$. The magnified error in the $y$-direction might be attributed to the slice spacing $(3 \mathrm{~mm})$. As Ney et al. [32] mentioned, the slice spacing influences the 3D accuracy of the volumetric display. Introductions of helical/spiral or cone-beam [33] CTs that reduce slice intervals will be able to increase the accuracy of the system and reduce irradiation to the patients. Recently, multimodal 3D data (CT, MRI, and/or MRA) fusion was also introduced to improve the accuracy of simulation and to apply to surgical navigation [34].
As the system was experimental, the exact cost for the simulation was not estimated. The time for the simulation was only $20 \mathrm{~min}$ on average. However, it was very timeconsuming to remove artifacts on each slice, construct models, segment bones, and so on. The total working time for each case was approximately $90-120 \mathrm{~min}$. Recently, the accurate $3 \mathrm{D}$ evaluation works in orthognathic surgery have been reported [35-37]. The integrated multimodal 3D data in this system may assist them. In addition, an exact simulation may help new surgical techniques like the endoscopic surgery or the piezosurgery in oral and maxillofacial region [38].

\section{Conclusion}

A new surgical simulation system, which enables precise calculation and visualization of the bony interference after surgery of the mandible, was presented. The accuracy of the system was proven to be clinically acceptable. This accuracy can be improved with more accurate CT hardware. The clinical trial revealed the usefulness of this surgical simulation system to predict proximal segment flaring or rotation from surgery for mandibular asymmetry, with which the system surgical method can be changed appropriately for the specific conditions of individual patients.

Acknowledgment This study was mainly performed at Osaka University and supported by the Industrial Technology Research Grant Program in 2001 from the New Energy and Industrial Technology Development Organization (NEDO) of Japan.

Conflict of interest No conflict exists.

Open Access This article is distributed under the terms of the Creative Commons Attribution Noncommercial License which permits any noncommercial use, distribution, and reproduction in any medium, provided the original author(s) and source are credited.

\section{References}

1. Cutting C, Bookstein FL, Grayson B, Fellingham L, McCarthy JG (1986) Three-dimensional computer-assisted design of craniofacial surgical procedures: optimization and interaction with cephalometric and CT-based models. Plast Reconstr Surg 77:877-885

2. Altobelli DE, Kikinis R, Mulliken JB, Cline H, Lorensen W, Jolesz F (1993) Computer-assisted three-dimensional planning in craniofacial surgery. Plast Reconstr Surg 92:576-585

3. Bettega G, Payan Y, Mollard B, Boyer A, Raphael B, Lavallee S (2000) A simulator for maxillofacial surgery integrating 3D cephalometry and orthodontia. Comput Aided Surg 5:156-165

4. Schendel SA, Montgomery K (2009) A web-based, integrated simulation system for craniofacial surgical planning. Plast Reconstr Surg 123:1099-1106. doi:10.1097/PRS.0b013e318199f653 
5. Marsh JL, Vannier MW (1983) The "third" dimension in craniofacial surgery. Plast Reconstr Surg 71:759-767

6. Girod S, Keeve E, Girod B (1995) Advances in interactive craniofacial surgery planning by $3 \mathrm{D}$ simulation and visualization. Int J Oral Maxillofac Surg 24:120-125

7. Fuhrmann RA, Frohberg U, Diedrich PR (1994) Treatment prediction with three-dimensional computer tomographic skull models. Am J Orthod Dentofacial Orthop 106:156-160

8. Kragskov J, Sindet-Pedersen S, Gyldensted C, Jensen KL (1996) A comparison of three-dimensional computed tomography scans and stereolithographic models for evaluation of craniofacial anomalies. J Oral Maxillofac Surg 54:402-411

9. Lill W, Solar P, Ulm C, Watzek G, Blahout R, Matejka M (1992) Reproducibility of three-dimensional CT-assisted model production in the maxillofacial area. Br J Oral Maxillofac Surg 30:233236

10. Grayson B, Cutting C, Bookstein FL, Kim H, McCarthy JG (1988) The three-dimensional cephalogram: theory, technique, and clinical application. Am J Orthod Dentofacial Orthop 94:327-337

11. Selvik G (1990) Roentgen stereophotogrammetric analysis. Acta Radiol 31:113-126

12. Kwon TG, Mori Y, Minami K, Lee SH, Sakuda M (2000) Stability of simultaneous maxillary and mandibular osteotomy for treatment of class III malocclusion: an analysis of threedimensional cephalograms. J Craniomaxillofac Surg 28:272-277. doi: $10.1054 /$ jcms. 2000.0158

13. Mori Y, Miyajima T, Minami K, Sakuda M (2001) An accurate three-dimensional cephalometric system: a solution for the correction of cephalic malpositioning. J Orthod 28:143-149

14. Okumura H, Chen LH, Tsutsumi S, Oka M (1999) Threedimensional virtual imaging of facial skeleton and dental morphologic conditions for treatment planning in orthognathic surgery. Am J Orthod Dentofacial Orthop 116:126-131

15. Kwon TG, Mori Y, Minami K, Lee SH (2002) Reproducibility of maxillary positioning in Le Fort I osteotomy: a 3-dimensional evaluation. J Oral Maxillofac Surg 60:287-293. doi:10.1053/ joms.2002.30583

16. Miyajima T (1996) Fundamental study of an integrated threedimensional measuring system for the oral and maxillofacial region. J Osaka Univ Dental Soc 41:167-187

17. Lorensen WE, Cline HE (1987) Marching cubes: a high resolution 3D surface construction algorithm. ACM Comp Graphics 21:163169

18. Hounsfield GN (1973) Computerized transverse axial scanning (tomography); part I. Description of system. Br J Radiol 46:10161022

19. Farmand M, Obwegeser H (1981) Unsere heutige Operationstechnik der sagittalen Spaltung. Fortschr Kiefer-Gesichts-Chir 26:99-101

20. Mori Y, Sugahara T, Hiraki T (1995) Improvement of a condylar positioning system for the mandibular ramus sagittal split osteotomy. J Oral Maxillofac Surg 53:340-341

21. Bell WM (1992) Morden practice in orthodontic and reconstructive surgery, vol 1. Saunders, Philadelphia, pp 521-593

22. Harris MD, Van Sickels JE, Alder M (1999) Factors influencing condylar position after the sagittal split ramus osteotomy fixed with bicortical screws. J Oral Maxillofac Surg 57:650-654
23. Morris JH, Albright JE, Brooks JH, Naito RL (1992) Prediction of ramus fragment relationship in surgical correction of facial asymmetries. Int J Adult Orthodon Orthognath Surg 7:25-250

24. Jensen J, Rieger W, Sindet-Pedersen S, Nørholt SE (1994) A simple model to show bony interference after sagittal split ramus osteotomy. J Oral Maxillofac Surg 52:1337-1340

25. Onish K, Maruyama Y (2001) Three-dimensional solid model integrated with dental model for maxillofacial surgery. Plast Reconstr Surg 108:1696-1699

26. Terai H, Shimahara M, Sakinaka Y, Tajima S (1999) Accuracy of integration of dental casts in three-dimensional models. J Oral Maxillofac Surg 57:662-665. doi:10.1016/S0278-2391(99)90425-1

27. Herman GT, Liu HK (1979) Three-dimensional display of human organs from computed tomograms. Comput Graphics Image Process 9:1-21

28. Schellhas KP, el Deeb M, Wilkes CH, Check RK, Larsen JW, Heithoff KB, Fritts HM (1988) Three-dimensional computed tomography in maxillofacial surgical planning. Arch Otolaryngol Head Neck Surg 114:438-442

29. Santler G, Kärcher H, Ruda C (1998) Indications and limitations of three-dimensional models in cranio-maxillofacial surgery. J Craniomaxillofac Surg 26:11-16

30. Carls FR, Schuknecht B, Sailer HF (1994) Value of threedimensional computed tomography in craniomaxillofacial surgery. J Craniofac Surg 5:282-288

31. Xia J, Ip HH, Samman N, Wang D, Kot CS, Yeung RW, Tideman H (2000) Computer-assisted three-dimensional surgical planning and simulation: 3D virtual osteotomy. Int J Oral Maxillofac Surg 29:11-17

32. Ney DR, Fishman EK, Magid D, Robertson DD, Kawashima A (1991) Three-dimensional volumetric display of CT data: effect of scan parameters upon image quality. J Comput Assist Tomogr $15: 875-885$

33. Grauer D, Cevidanes LSH, Proffit WR (2009) Working with DICOM craniofacial images. Am J Orthod Dentofac Orthop 136:460-470

34. Kockro RA, Tsai YT, Ng I, Hwang P, Zhu C, Agusanto K, Hong LX, Serra L (2009) DEX-RAY: augmented reality neurosurgical navigation with a handheld video probe. Neurosurg 65:795-808

35. Laudemann K, Petruchin O, Mack MG, Kopp S, Sader R, Landes CA (2009) Evaluation of surgically assisted rapid maxillary expansion with or without pterygomaxillary disjunction based upon preoperative and post-expansion 3D computed tomography data. Oral Maxillofac Surg 13:159-169. doi:10.1007/s10006-009-0167-3

36. Laudemann K, Petruchin O, Nafzger M, Ballon A, Kopp S, Sader RA, Landes CA (2010) Long-term 3D cast model study: boneborne vs. tooth-borne surgically assisted rapid maxillary expansion due to secondary variables. Oral Maxillofac Surg 14:105114. doi:10.1007/s10006-009-0194-0

37. Nkenke E, Variaktaris E, Kramer M, Schlegel A, Holst A, Hirschfelder U, Wiltfang J, Neukam FW, Stamminger M (2008) Three-dimensional analysis of changes of the malar-midfacial region after Le Fort I osteotomy and maxillary advancement. Oral Maxillofac Surg 12:5-12. doi:10.1007/s10006-008-0094-8

38. Landes CA, Stübinger S, Ballon A, Sader R (2008) Piezoosteotomy in orthognathic surgery versus conventional saw and chisel osteotomy. Oral Maxillofac Surg 12:139-147. doi:10.1007/ s10006-008-0123-7 